\section{Qualitative Modelling of Gold Mine Impacts on Lihir Island's Socioeconomic System and Reef-Edge Fish Community}

\author{
JEFFREY M. DAMBACHER, *, \\ DAVID T. BREWER, \\ DARREN M. DENNIS, \\ MARTHA MACINTYRE, \$ AND \\ S I M O N F O L E ${ }^{\perp}$
}

CSIRO Marine and Atmospheric Research, GPO Box 1538, Hobart, Tasmania 7001, Australia, CSIRO Marine and

Atmospheric Research, 233 Middle Street, Cleveland, Queensland 4163, Australia, Centre for Health and Society, University of Melbourne, 207 Bouverie Street, Melbourne, Victoria 3010, Australia, and Research School of Pacific and Asian Studies, Australian National University, Canberra, Australian Capital Territory 0200, Australia

Inhabitants of Lihir Island, Papua New Guinea, have traditionally relied on reef fishing and rotational farming of slash-burn forest plots for a subsistence diet. However, a new gold mine has introduced a cash economy to the island's socioeconomic system and impacted the fringing coral reef through sedimentation from the near-shore dumping of mine wastes. Studies of the Lihirian people have documented changes in population size, local customs, health, education, and land use; studies of the reef have documented impacts to fish populations in mine affected sites. Indirect effects from these impacts are complex and indecipherable when viewed only from isolated studies. Here, we use qualitative modelling to synthesize the social and biological research programs in order to understand the interaction of the human and ecological systems. Initial modelling results appear to be consistent with differences in fish and macroalgae populations in sites with and without coral degradation due to sedimentation. A greater cash flow from mine expansion is predicted to increase the human population, the intensity of the artisanal fishery, and the rate of sewage production and land clearing. Modelling results are being used to guide ongoing research projects, such as monitoring fish populations and artisanal catch and patterns and intensity of land clearing.

\section{Introduction}

Lihir Island is situated in Papua New Guinea's New Ireland Province and is the site of the Lihir Gold Mine (Figure 1), which operates in one of the world's largest gold deposits (1). Mine construction began in 1995; active operations commenced in 1997 and are expected to continue until at least 2042 (2). Both the island's inhabitants and environment

\footnotetext{
* Corresponding author phone: 6136232 5096; fax: 6136232 5000; e-mail: jeffrey.dambacher@csiro.au.

+ CSIRO Marine and Atmospheric Research, Hobart.

‡ CSIRO Marine and Atmospheric Research, Cleveland.

$\S$ University of Melbourne.

${ }^{\perp}$ Australian National University.
}

have been heavily impacted by the mine. For example, the population has doubled; mine royalty and compensation payments have shifted the economy from barter to cash; and mine wastes from the more than 40 million tons of material extracted each year are disposed of into the ocean. The effects of mine wastes on the biota of shallow $(<20 \mathrm{~m}$ depth) and deepwater (20-320 $\mathrm{m}$ depth) habitats were measured by comparing the abundance of fish species at different distances from the disposal site (3). Concurrently, there has been a study of the effects of the gold mine on the Lihir islanders' use of natural resources, both on land and in near-shore marine environments (4). Both studies identified specific impacts of the gold mine, but a working model is needed to help understand the complex interactions of the gold mine, the marine resources, and island communities and to predict future impacts on the island's natural and social systems.

Modelling that ignores complexities of cultural value systems and how these determine economic activity and resource consumption and focuses instead on measurable "facts" such as population numbers, invariably oversimplifies the relationship between the social (which is determined by humans) and the ecological (which includes humans). Biologists are typically suspicious of the findings of social scientists that cannot be enumerated, whereas social scientists can be critical of biological studies claiming to include "social factors" yet excluding a crucial human capacity: to learn from the findings of research and change behavior. And although research programs are typically constrained into specialized disciplines, they often externalize important factors and exclude key links to other systems. Such omissions can lead to management decisions with insufficient context, thereby contributing to a syndrome of natural resource usage lacking in ecological sustainability and social equity (5).

The present study synthesizes the results from both biological and socioeconomic research programs by applying general causal models that incorporate a whole-system approach to understanding the mine's impacts on the shallow-water reef-edge fish community and the socioeconomic system of Lihir Island. Understanding and predictions gained from these models will be used to determine and prioritize the direction of future research.

Nature and society can be overwhelming in their complexity; well-meaning or reasoned interventions can have counterintuitive outcomes that emerge from complex feedbacks inherent to system dynamics (6). The construction of dynamic models of biological or socioeconomic systems is severely limited by the difficulty of measuring system variables and interaction strengths $(7,8)$. Fortunately, although we usually cannot precisely measure the magnitude of all variables in a system or their interaction strengths, we often have extensive qualitative information of systems obtained by general observation. Qualitative models work without measuring system parameters and instead rely on the general shape of functions that mediate relationships between variables (7). In sacrificing precision, they seek to maximize generality in a causal understanding of complex systems. This means they permit the inclusion of relevant but often immeasurable details in order to capture the structural aspects and essential dynamics of the whole system (9).

Qualitative models of dynamic systems were first advanced in an economic setting by Samuelson (10) and Quirk and Ruppert (11) to capture the equilibrium behavior of linerized systems. Levins $(12,13)$ elaborated this approach into a biological and evolutionary context through the use 


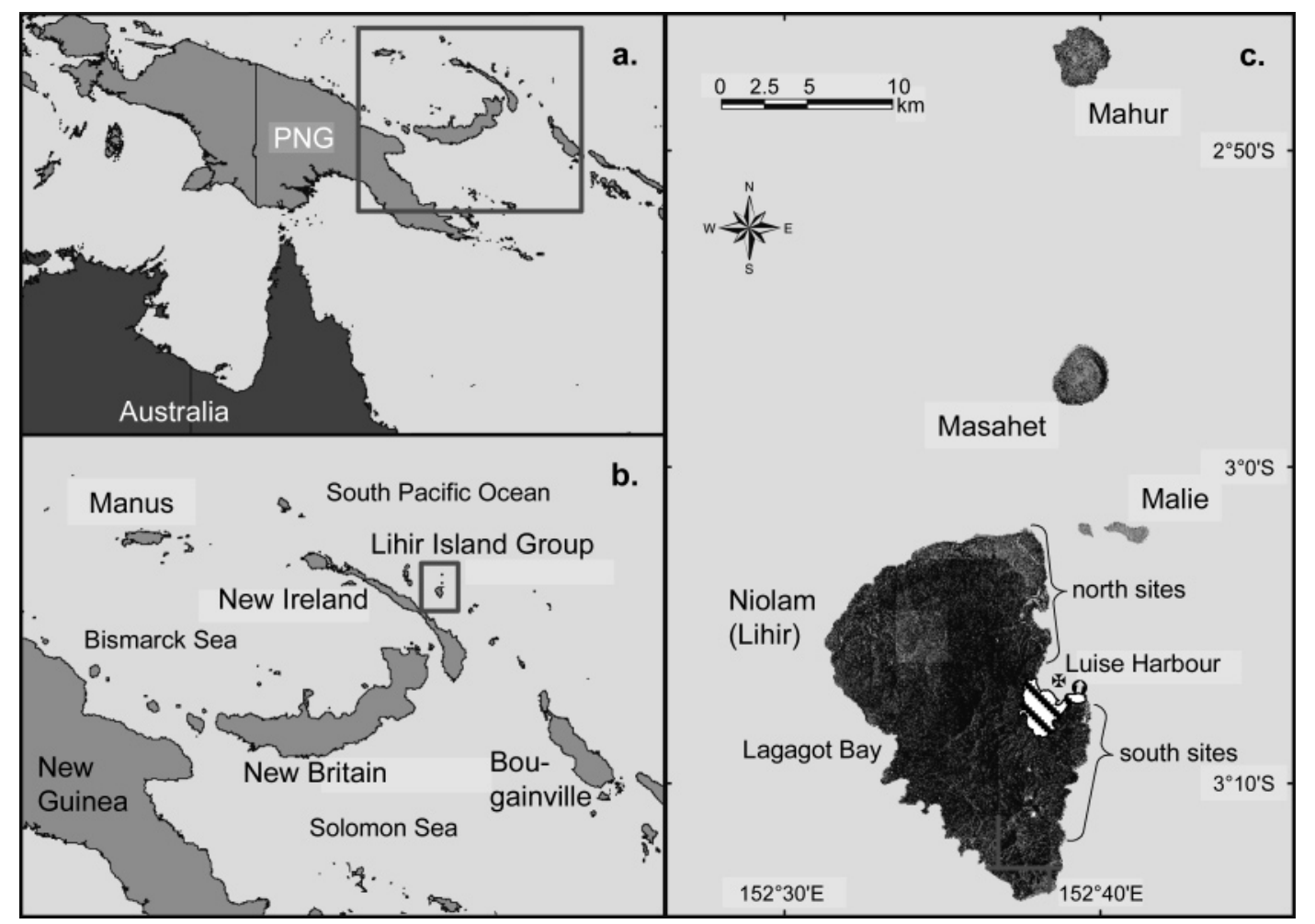

FIGURE 1. Location of (a) Papua New Guinea's (PNG) Lihir Island group showing (b) its position north east of New Ireland in the South Pacific Ocean, and (c) the four islands of the group. The central east coast of Niolam Island, also known as Lihir Island, is the site of a gold-mining operation (hatched area) from which mine wastes are barged to a dumpsite in Luise Harbor (marked by a cross) and mine slurry tailings are deposited through a pipeline at $128 \mathrm{~m}$ depth (marked by an arrow). Shallow-water ( $<20 \mathrm{~m}$ depth) reef-edge fish communities were sampled to the north and south of the mine; the former are affected by sediment transported from the dumpsite by northerly ocean currents.

of graphical algorithms, which have variously been termed "loop analysis" and "qualitative modelling". Here, the focus is on feedbacks in the system that emerge from pathways of interactions between variables. Analysis of these feedbacks is used to determine the conditions for system stability and make predictions of how a system will respond to a perturbation. Qualitative modelling has also been extended to address variables that display sustained bounded motion, such that they are held or forced away from equilibrium as a result of deterministic or stochastic processes $(9,14)$. More recently, qualitative simulation techniques have been developed in the field of artificial intelligence (15) that allow description of the possible behaviors and states of systems that are far from equilibrium and nonlinear. This technique relies on the identification of critical thresholds in the functional relationship between variables, which are used to define general states of a system. The direction of change in variables is then determined for each state, thus leading to predictions of the time-dependent behavior and possible transition states when a threshold is passed. This approach has seen an increasing application in the fields of economics (16), ecology (17), and fisheries (18). In this work, we are concerned with changes in equilibria resulting from impacts of the Lihir Island gold mine, and thus examine the consequence of these impacts through Levin's qualitative modelling technique.

\section{Methods}

System Structure and Signed Digraphs. Qualitative modelling proceeds by first determining system structure, which is defined by the variables of the system and the relationship by which they are linked. In biological systems, variables are typically interacting populations of different species, and their dynamics can be accounted for by generalized Lotka-
Volterra equations, wherein each contributes toward the birth or death of another. Similarly, the dynamics of human social and economic systems can be described by the interactions of different sectors and entities of society (e.g., such as governing bodies, social customs, and markets) that control flows of resources, goods, and services that are either measurable, such as money (19), or immeasurable, such as status and world view (20-22). The variables and relationships are portrayed by sign-directed graphs, or signed digraphs, where a link from one variable to another ending in an arrow $\rightarrow$ ) represents a positive direct effect, such as births produced by consumption of prey, and a link ending in a filled circle $(-\bullet)$ represents a negative direct effect, such as death from predation. All possible ecological relationships can thus be described: predator-prey or parasitism $(\bullet)$, mutualism $(\leftrightarrow)$, commensalism $(\rightarrow)$, interference competition $(\bullet \bullet)$, and amensalism $(\bullet)$. Self-effects are shown by links originating and ending in the same variable, and are typically negative as in self-regulated variables, but can also be positive where variables are self-enhancing. Usually, we restrict ourselves to linear relationships between species, although nonlinear relationships (e.g., functional responses) can also be incorporated. Here, the sign of a relationship can change when the system passes a threshold. This then leads to construction and analysis of alternative model structures.

Once the structure of a system is defined, it is possible to analyze the system's feedback, which determines the qualitative conditions for system stability and perturbation response. These methods can proceed via analysis of the signed digraph through graphical algorithms or through equivalent algebraic analyses of the system's community matrix. In this work, we proceed with analysis of signed 
digraphs and present only the basic principles required to understand our analysis of the Lihir Island models. In Appendix 1 is presented a more detailed treatment of the mathematics involved; see also refs $9,13,23,24$. Additionally, computer programs for qualitative analyses can be found in the most recent revision of Supplement 1 of Dambacher et al. (23) in Ecological Archives E083-022-S1 at http://www. esapubs.org/archive/.

As an illustrative example, we consider a signed digraph of a predator-prey community of size $n=3$, where the top predator is an omnivore that feeds on the basal species:

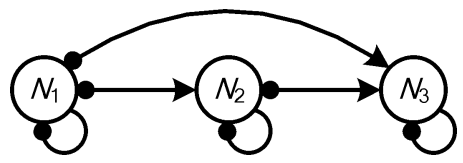

System Stability. Our first task is to identify whether the model system is sign stable (11), such that its stability is assured no matter what parameter space the system occupies, or if the system's stability is conditional, in which case its stability depends on specific symbolic inequalities. The stability of a system can be judged and understood according to criteria that depend on the relative sign and balance of the system's feedback cycles $(9,12,13,24)$. In general, stability requires that the net feedback in a system is negative and that feedback at lower levels is stronger than feedback at higher levels in the system. Negative feedback ensures that a system's dynamics are self-damped, and stronger feedback at lower levels ensures that a system will not overcorrect and exhibit unrestrained oscillations. The conditions can be interpreted through specific algebraic arguments, which, for this example system, are presented in Appendix 1. In general, though, stability in this system depends on the relative weakness of feedback cycles involving omnivory. Here, the feedback cycle $+a_{3,1} a_{1,2} a_{2,3}$ has the potential to destabilize the system through positive feedback, and the feedback cycle $-a_{2,1} a_{1,3} a_{3,2}$, even though it is negative in sign, has the potential to introduce excessive higher-level feedback if it is too strong.

Perturbation Response. We next seek to predict how population levels in the system change as a result of a sustained change to a rate of birth, death, or migration of one of the species $(9,13,23)$. As an example perturbation scenario, we consider a positive input to $N_{2}$, such as food supplementation, that increases its rate of birth. The qualitative effect of this input to the other variables is determined by accounting for all of the feedback cycles of length $n-1$ that emanate from $N_{2}$. This is accomplished by tracing all paths from the input variable to a responding variable and multiplying each path by the feedback of its complementary subsystem; the resulting product is defined as a feedback cycle. The complementary subsystem is defined by the variables not on the path from the input to the response variable. If the sign of this subsystem's feedback is positive, then it will switch the sign of the path to the response variable; otherwise, the sign of the path will be unchanged. The signed digraphs below illustrate the formation of feedback cycles that are used to predict perturbation response. All links that enter the input variable and all links leaving the response variable have been removed; products of the remaining links then become the feedback cycles that determine the sign of the response. For response of $N_{1}$ feedback cycles will be composed of the following links:

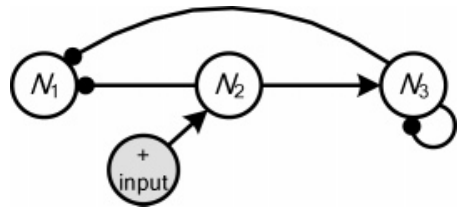

Here, two feedback cycles determine the sign of the response of $N_{1}$ due to an input to $N_{2}$. One feedback cycle, $-a_{1,2} a_{3,3}$, is formed by a path that goes directly from $N_{2}$ to $N_{1}$ and has a complementary subsystem in the negative self-effect of $N_{3}$. The other cycle, $-a_{3,2} a_{1,3}$, is composed of a path with a negative sign of length two. This path lacks a complementary subsystem, in which case the sign of the path remains negative. Because both feedback cycles are negative, the equilibrium abundance of $N_{1}$ is predicted to decrease as a result of supplementing of $N_{2}$.

Next, we consider the response of $N_{3}$ when there has been a negative input to $N_{2}$, say, through an increased rate of death through culling, and note that for negative inputs, the signs of the feedback cycles are switched. The sign of the response of $N_{3}$ is determined by the following links

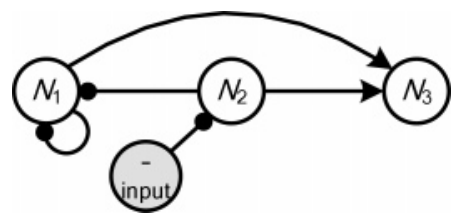

which form feedback cycles $+a_{1,2} a_{3,1}$ and $-a_{3,2} a_{1,1}$. Here ,the response is ambiguous, as it is determined by feedback cycles of opposing sign.

Ambiguity and Weighted Predictions. The ambiguity in the response of $N_{3}$ can be resolved through consideration of symbolic inequalities. For instance, if it is believed that $a_{3,2} a_{1,1}$ $>a_{1,2} a_{3,1}$, then the predicted response of $N_{3}$ will be negative. Dealing with ambiguity in this manner requires a relative knowledge of interaction strengths and an ability to make sense of contingencies presented by symbolic arguments. However, in larger systems, complex inequalities can arise that are too difficult to interpret or comprehend. In these instances, we can employ a heuristic technique of weighting the net number of feedback cycles to the absolute number in a response, i.e., the weighted prediction for a response prediction is equal to the net number of feedback cycles divided by the total number of cycles (23). For instance, the predicted response of $N_{3}$ for an input to $N_{2}$ is completely ambiguous, as there is the same number of positive and negative feedback cycles. But if there were, say, a total of four feedback cycles in a perturbation response, three of which were positive and one negative, then the net number of cycles would be two and the weighted prediction of the response would be $2 / 4=0.5$. The sign determinacy of responses with weighted predictions $\geq 0.5$ has been shown to generally be $>90 \%$ through simulations using random parameter space (25); below this threshold, the sign determinacy of responses declines to zero for weighted predictions equal to zero.

Model Construction. A model of the reef-edge fish community was based on the main functional groups of organisms associated with corals in shallow water. Construction of the model was based on information collected by a SCUBA diver census of conspicuous fishes and habitat types during 1999-2002 (3). Fish abundance and habitat data were collected at 171 reef-edge sites along belt transects $100 \mathrm{~m}$ long and $10 \mathrm{~m}$ wide. The divers estimated the numbers of all fish species observed in each transect. The reef-edge habitat at each site was characterized by the percentages of cover of standard abiotic and biotic categories, such as live and dead standing coral, and a visibility index. Fish species were combined into functional groups (see Table S1 in the Supporting Information) on the basis of their feeding habits, as interpreted through FishBase (26), and associations with coral habitat (27). These groups were the variables used in the qualitative models.

VOL. 41, NO. 2, 2007 / ENVIRONMENTAL SCIENCE \& TECHNOLOGY - 557 
a. shallow-water reef-edge fish community

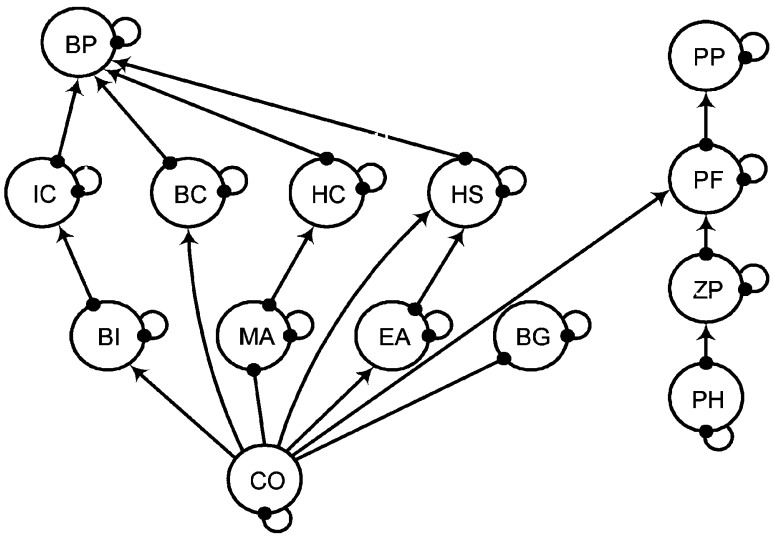

b. socioeconomic system

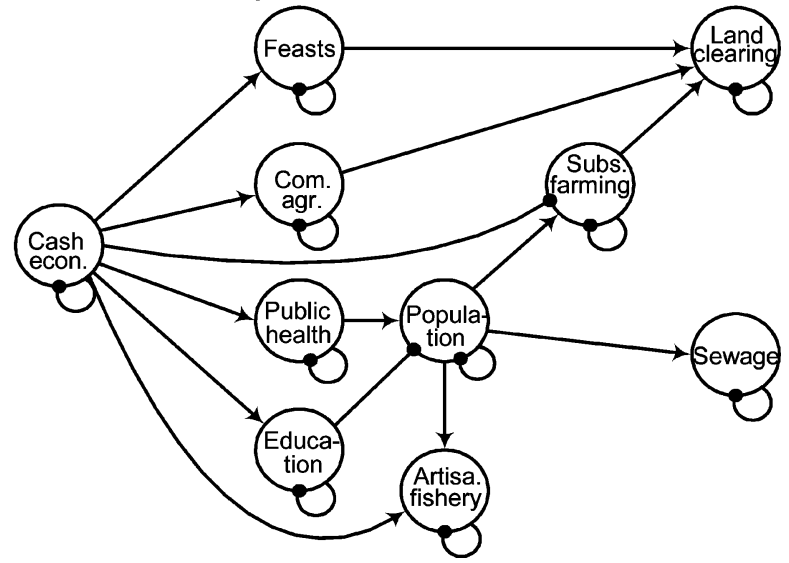

FIGURE 2. Signed digraphs of (a) shallow-water reef-edge fish community and (b) the socioeconomic system of Lihir Island, Papua New Guinea. Open circles are system variables, links ending in an arrow denote a direct positive effect from one variable to another, links ending in a filled circle denote a direct negative effect, and a link connecting a variable to itself denotes self-regulation. Legend: Artisa. = artisanal; $\mathbf{B C}=$ benthic coral cropper; $\mathbf{B G}=$ blue-green algae; $\mathrm{BI}=$ benthic invertebrates; $\mathrm{BP}=$ benthic piscivorous fish; $\mathrm{CO}=$ coral; $\mathrm{EA}=$ epiphytic algae; econ. = economy; HC = herbivorous cropper (fish); HS = herbivorous scraper (fish); IC = benthic invertebrate consumer (fish); MA = macroalgae; PF $=$ planktivorous fish; $\mathrm{PH}=$ phytoplankton; $\mathrm{PP}=$ pelagic piscivorous fish; ZP = zooplankton; Com. agr. = commercial agriculture; Subs. = subsistence.

The qualitative model of the shallow-water reef-edge fish community had 14 population variables for benthic and pelagic species associated with coral reefs (Figure 2a). Coral is eaten by benthic coral croppers (such as butterfly fishes Chaetodontidae), but as they do not impart a death rate to coral, the relationship is depicted as being commensal. Other relationships were determined on the basis of coral providing refuge habitat to invertebrates, juvenile herbivorous scrapers (such as parrot fishes Scaridae), and planktivorous fishes (such as the damselfishes Pomacentridae) and being a substrate for growth of epiphytic algae (27). In contrast, coral's allelopathic effects (28) inhibit the establishment and growth of most macroalgae and some forms of blue-green algae. Self-regulation of the basal variables represents intraspecific competition for space as well as use of resources that are limited, such as sunlight and nutrients. Similarly, selfregulation in the fish and invertebrate species groups represents intraguild competition and predation, nonlocal recruitment, and consumption of resources from outside the model system. This model was sign stable, and can be seen to be composed of benthic and pelagic subsystems reliant, in part, on live coral communities for either food or habitat.

A socioeconomic model (Figure $2 b$ ) was constructed from observations and survey data gathered during the study of impacts of the gold mine on the resource use and culture of Lihir Islanders (29). The model was also sign stable and reflects the major causal links connecting cultural norms and attitudes toward land and resource use, as affected by a new cash economy. A cash economy has grown with the advent of the gold mine industry, which infuses cash into the island economy from royalty and compensation payments, and from employment by the mine and support industries. The cash economy variable in Figure $2 \mathrm{~b}$ represents the per capita available wealth and funds available for public services and works. The provision of health services has generally had a positive influence on public health: life expectancy of Lihirians has increased from 54 to 64 years in the past decade. However, changes in nutrition associated with the capacity to purchase food, especially protein-rich foods such as meat and fish, and increased consumption of fat and sugar are contributing to a transition in health: causes of morbidity and mortality are shifting from contagious and parasitic diseases such as tuberculosis, malaria, and filariasis to degenerative diseases such as cardiovascular diseases, diabetes, and cancer. The birth rate of the population is expected to decline when women (especially) obtain more education, but for now this effect is thought to be weak. Self-regulation in the socioeconomic model implies that variables are controlled by processes and limits not associated with the other model variables, i.e., expansion of arable lands is limited by the island's steep terrain and erodable soils, and apart from monetary influences, there is clan level support of human health, education, and sewage control, as well as customary regulation of access to farm plots and reef fishing sites.

There has been some development in commercial agriculture due to the cash economy. There has also been a slight reduction in subsistence farming, which traditionally has grown a variety of food plants on family plots, systematically rotating the plantings and leaving plots fallow for up to 10 years. Land is also cleared to cultivate special yam (Dioscorea alata) gardens in preparation for feasts, which are important in New Guinean culture (20) and a competitive means of attaining social status (30). Families preparing the most lavish feasts acquire wider control and use of common lands, primarily through acreage devoted toward yam production. Preparations for a feast take about a year and start with slashburn clearing of forested or fallow land to plant the yams. Some of the yams are used to grow pigs (Sus scrofa vittatus) destined for the feast, and both yams and pigs are then presented at the feast on behalf of the clan (Figure 3a). Pigs traditionally were difficult to obtain when they were bred only on Lihir Island, but now can be readily imported from neighboring islands through cash purchases. Hence, with the recent infusion of cash into the economy, there has been an expansion of competitive feasting on Lihir Island. This in turn has contributed to a dramatic increase in the clearing of forest land and reduction in the duration of fallow periods. There has also been an increase in immigration to Lihir Island but, as many migrants cannot find paid employment, they have added to the pressure on land for local subsistence production.

The effect of the increase in the human population was depicted in the model as influencing the production of sewage and the intensity of subsistence farming and artisanal fisheries. Artisanal fishing pressure, in turn, has been increased by the cash economy through acquisition of small boats, outboard motors, and fishing gear. However, most harvesting on shallow reefs is done by spears, handlines, and reef-walking at night. The fishery targets the invertebrate 

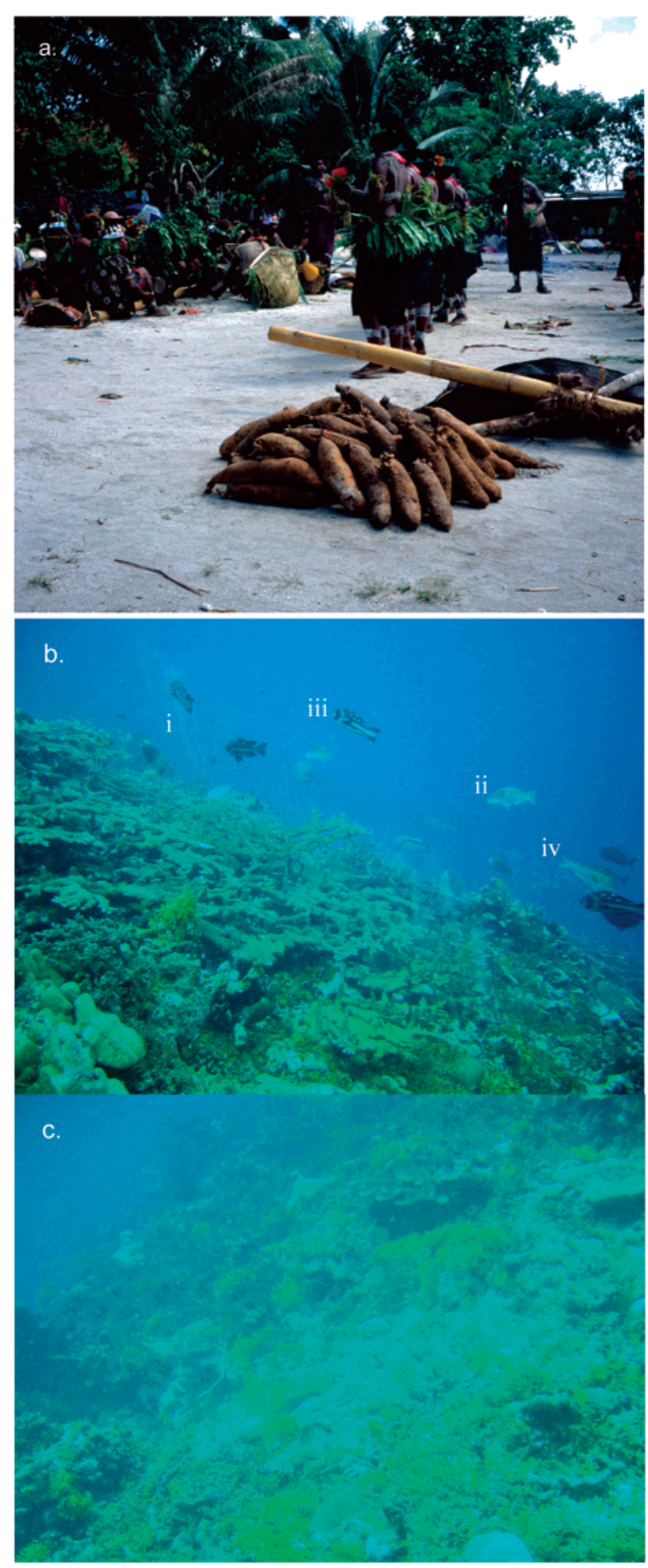

FIGURE 3. (a) Pile of yams (Dioscorea alata) and a pig (Sus scrofa vittatus) presented on behalf of one of several clans at a mortuary feast on the island of Malie in the Lihir Island Group, 2003. Photograph (b) is representative of coral reef unaffected by mine sediment in sample sites south of Lihir Gold Mine (Figure 1). Photograph (c) shows turbid water over a reef north of the mine that is also partially smothered by sediment and colonised by macroalgae. In (b): (i) feeding trail from a parrot fish, comprising crushed coral sand used to aid digestion of epiphytic algae, (ii) the parrot fish Chlorurus microrhinos, an herbivorous scraper, and benthic invertebrate consumers (iii) Macolor macularis and (iv) Monotaxis grandoculis. Photo credits: (a) S.F. (b, c) D.M.D.

consumer and herbivorous cropper trophic guilds because of their relatively large size and vulnerability to fishing. This fishing is mainly noncommercial; instead, it is a means of supplementing household diets for a few meals a week (3). Through the artisanal fishery, there is an interaction between, and thus a joining of, the socioeconomic system and the shallow-water reef-edge fish community.

Interpretation of Ecosystem Response. In a process separate from model construction, model predictions were compared to differences between sites with and without observable impacts from mine sediments. Sample sites of shallow-water reef-edge habitats (Figure 1) were divided between areas south of the dumpsite unaffected by the northflowing sediment plume and sites north of the dumpsite, where chronic, but not overwhelming, effects from turbidity and sedimentation of bottom substrate and corals were observed (Figure 3c). Sites close to the mine waste dumpsite in Luise Harbor were excluded from the comparison because they were completely covered by sediment deposits and thus not representative of any other region of Lihir Island. The abundances (no. ha ${ }^{-1}$ ) of the 15 most common species were analyzed to represent the mean response of three functional groups to the influence of the mine. The perturbation response for mine effects was thus calculated as a simple statistical comparison (i.e., without replication) of a northminus-south value of average abundance for each functional group. Although there was no formal census of macroalgae, photographs show dramatic differences in their abundance between sites affected and unaffected by mine sediments.

\section{Results}

Mine impacts on reef-edge fish communities were considered in two perturbation scenarios (parts a and b of Figure 4). In the first, mine sediment has a negative effect only on coral, through smothering $(31,32)$; in the second, there is an additional negative effect on all primary producers, including phytoplankton, due to the shading effect of turbid water. Predictions from both of these scenarios are similar, and for the most part differ only in the level of ambiguity for some of the predicted responses. The main exception is the response of macroalgae, which is predicted to increase in the first scenario but decline in the second. The predicted increase of macroalgae under scenario 1 is via alleviation of the suppressive effects of coral, although this response is countered to a lesser extent by an increase in herbivorous croppers. In the second scenario, a negative response in macroalgae is driven by the suppressive effects of turbidity and an increase in herbivorous croppers. The predicted increase in pelagic zooplankton in scenario 1 is due to reduced predation from planktivorous fishes reliant on coral habitat, whereas their decrease in scenario 2 is due to the suppression of phytoplankton by turbidity.

Model predictions in parts a and b of Figure 4 were consistent with the observed difference in fish abundance between sites affected and unaffected by mine sediments. Both models predicted, with varying degree of ambiguity, lower abundances of benthic invertebrate consumers and herbivorous scrapers and a higher abundance of herbivorous croppers in mine-affected sites; none of these differences, however, were statistically significant ( $\alpha=0.05$, see Figure S1 in the Supporting Information). Although there were no quantitative measurements of macroalgae cover, photographs (e.g., images b and c of Figure 3) indicate that macroalgae abundance in mine-affected sites was much greater than in unaffected sites. This difference is consistent with perturbation scenario 1 but not 2 and supports the hypothesis that the main effect of mine sediments on the shallow reefs is the smothering of corals, but not the suppression of primary production by shading from turbidity.

A third perturbation scenario (Figure 4c) considers the impact of increased artisanal fishing on two groups of fishesbenthic invertebrate consumers and herbivorous croppersin sites unaffected by mine sediments. This increase was 
a. perturbation scenario 1

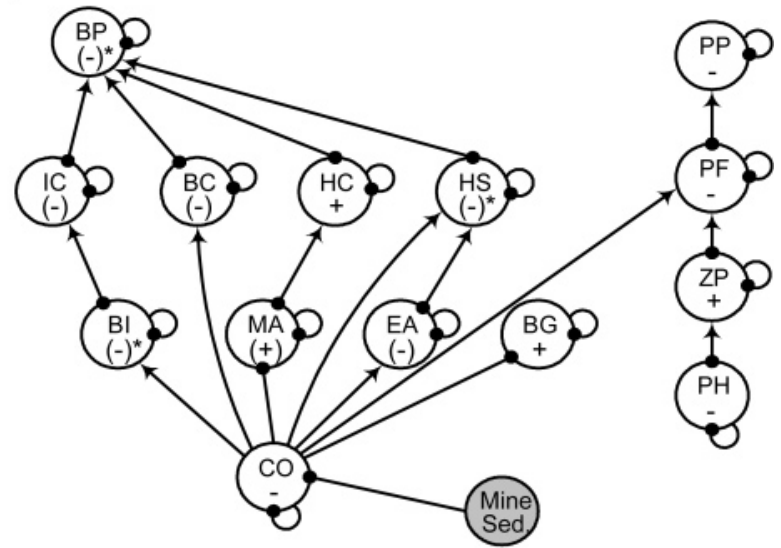

b. perturbation scenario 2

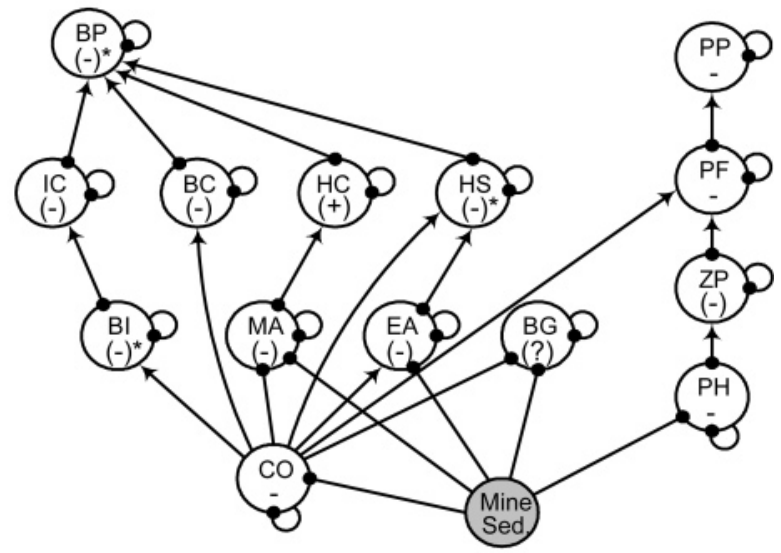

c. perturbation scenario 3

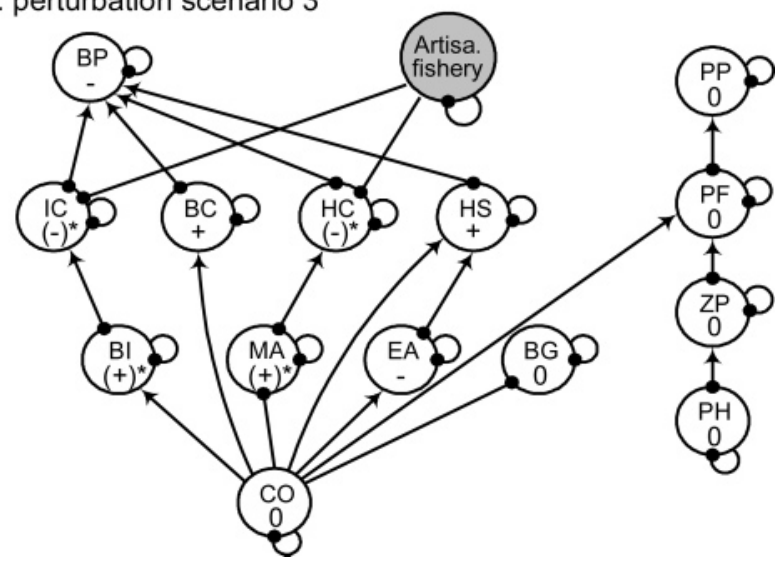

FIGURE 4. Perturbation scenarios for fish community model of Figure 2a. Shaded circles represent the source of perturbation to death rate parameters of specific model variables. (a) Scenario 1, mine sediment (Sed.) smothers coral; (b) scenario 2, turbidity also inhibits primary production; and (c) scenario 3, there is an increase in artisanal fish harvest. Predictions of perturbation response for direction of change $(+,-$, or 0$)$ are shown for each variable. Conditional predictions are enclosed by parentheses; those with an asterisk have high sign determinacy (weighted predictions $\geq 0.5$ ), those without an asterisk have low sign determinacy (weighted predictions $<0.5$ ), and "?" are completely ambiguous (weighted predictions $=0$ ).

predicted from the infusion of cash into Lihir Island's economy (Figure 5), which results in increased effort because of the availability of fishing equipment. This increase can be accounted for by a negative input to the two groups of fishes targeted by artisanal fishers. Although this scenario depicts the fishery as a perturbation, it is in fact a variable linking a.

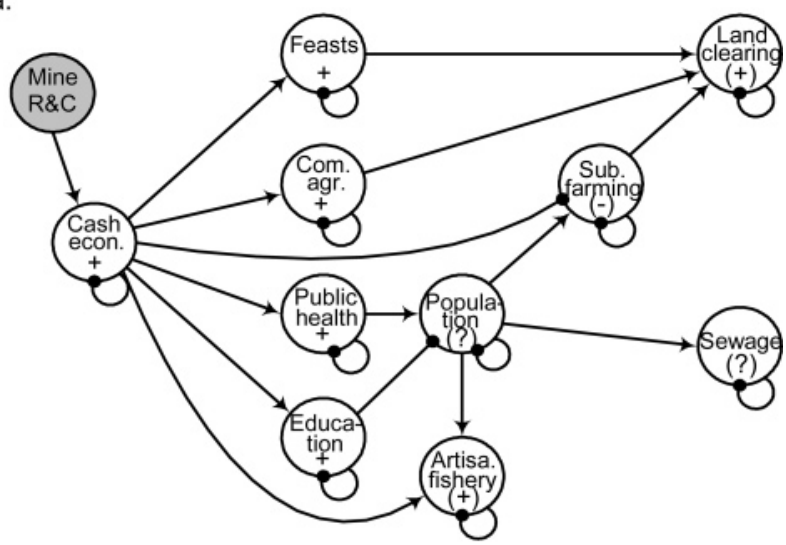

b.

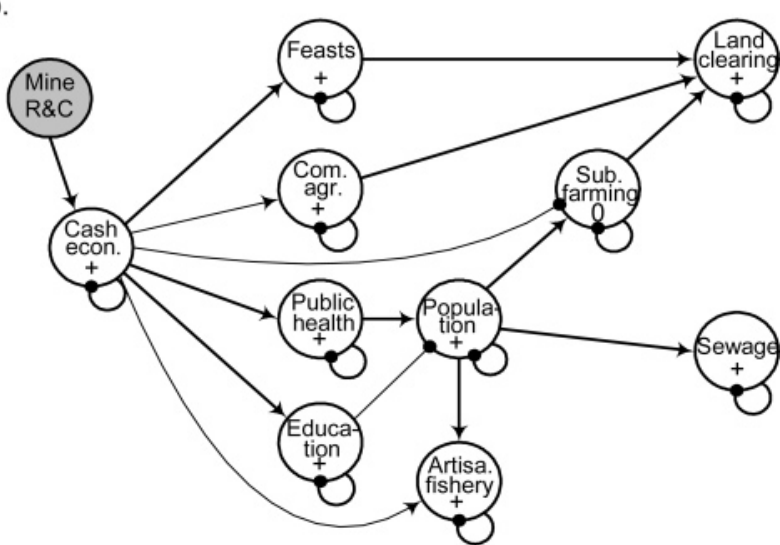

FIGURE 5. Perturbation scenarios for socialeconomic model of Figure $\mathbf{2 b}$. Shaded circle represents source of perturbation; here, it is from the flow of money into the island's cash economy from royalties and compensation paid by the local gold mine industry (Mine R\&C). (a) Ambiguous predictions are shown as in Figure 4, and (b) ambiguities are resolved by assumption of relatively weak interaction strengths between some variables, as shown by links with thin lines.

the socioeconomic system to the shallow-water reef-edge fish community. The model predicts, in Figure 4c, a decline in the abundance of the two target fish guilds and an increase in the abundance of benthic invertebrates and the standing crop of macroalgae. The abundances of benthic coral croppers, benthic invertebrates, herbivorous scrapers, and macroalgae are all predicted to increase with reduced predation pressure, whereas the abundances of benthic piscivorous fish and epiphytic algae are predicted to decrease. The abundances of all other variables in the model are predicted to remain unchanged.

Perturbation of the socioeconomic model by cash payments from the gold mine industry in Figure 5a resulted in predictions with ambiguity that was resolved in Figure $5 \mathrm{~b}$ by the assumption of weak interactions between six variables: between the cash economy and agriculture, subsistence farming, and artisanal fisheries, and also between education and population size. With these assumptions, the model predicts increases in the size of the human population, the intensity of artisanal fisheries, the production of sewage, and the rate of land clearing. However, the intensity of subsistence farming is predicted to remain unchanged, as cash income is viewed as a means to buy "luxury foods" (meat, sugar, soft drinks) and the woman's role remains that of "gardener", producing staple starchy foods for the household. The feast gardening component and duration of competitive exchange cycles ensure, however, that the areas of land cleared and planted each year are likely to increase. 


\section{Discussion}

In this work, we have used qualitative modelling to synthesize research on the effects of the gold mine on Lihir Island's socioeconomic system and its shallow-water reef-edge fish community. Model predictions were generally consistent with observed differences in fish abundance between mineaffected and unaffected sites. However, primarily as a result of high within-guild variance, the observed differences for fishes were not statistically significant and thus do not in themselves provide a convincing test of model predictions. There was, however, strong evidence that macroalgae was more abundant in mine-affected sites, which lends support for the model's prediction, via perturbation scenario 1 , that the main effect of the mine is through sedimentation of coral. Ongoing annual monitoring of the reef-edge fish community is being adjusted to address the high within-guild variance of the fishes.

When the combined impact of mine sediments and artisanal fishing (by adding perturbation scenarios 1 and 3 in Figure 4) are considered, benthic invertebrate consumers are predicted to decrease. As artisanal fishing pressure is also predicted to increase (with growth in the human population), this group of fishes will need careful monitoring, especially in mine-affected areas. Other fish guilds may be of less concern, having opposing predictions for the effects of the mine and artisanal fishing. Herbivorous croppers are predicted to increase in mine-affected areas, but decrease as a result of an increase in artisanal fishing. The predictions are reversed for benthic coral croppers and herbivorous scrapers.

A planned expansion of the mine operation (2) is expected to add to the mine's workforce population, and will also increase the disposal of mine sediments and the infusion of cash into the island's economy. For the latter effect, our qualitative analyses support predictions of continued growth in the human population and intensity of land clearing on Lihir Island, which are expected to increase both the sediment loads from land clearing and the sewage input to the reef edge. The combined impact of all these effects can be viewed as feedback to the reef-edge community model in Figure 2a that connects it to the socioeconomic model in Figure $2 \mathrm{~b}$. Here, we consider that nutrients from sewage might enhance primary production (33), and thus we could add positive effects from sewage to macroalgae, epiphytic algae, bluegreen algae, and phytoplankton. Additionally, sediment from land erosion and mine wastes might suppress coral, thus creating a negative effect from the land-clearing variable on corals. Qualitative analyses from a combined model, or of other models with alternative structures and links, can then be used to plan and help implement future research on the reef-edge system. As more detailed demographic information for Lihir Island is becoming available, and as factors affecting and interacting with demographic effects are identified, modelling could incorporate more subtle interactive relationships and trends in the environmental impacts that are attributable to socioeconomic factors.

The modelling presented here is a first attempt to describe the interactions of the mine, the local communities, and the shallow-water fish resources. The resulting models are, by design, simplifications to achieve an intermediate level of complexity. The models also provide a structure for generating and testing hypotheses, a strategic framework for data collection, and a foundation for iterations of model building and validation. Future work could also be directed toward developing models to account for possible feedbacks to the marine environment from erosion induced by land clearing and from sewage production. The model could feasibly be elaborated to include the results of new social research on attitudes toward money as well as demographic data on land use and agricultural practices. This approach has the potential to provide an understanding of system dynamics and a predictive capacity to manage the interactions, especially as research on each of the component activities and resources is expanded in the years ahead.

\section{Acknowledgments}

We thank S. Blaber, V. Mawson, C. Wilcox, and two anonymous reviewers for helpful comments on an earlier draft of this work.

\section{Supporting Information Available}

Supporting Information includes (1) matrix algebra methods for qualitative analyses of stability and perturbation response of model systems, (2) a listing of all fish species observed and their trophic guild designations, and (3) abundance with standard error of fish guilds observed at mine-affected and unaffected sites. This material is available free of charge via the Internet at http://pubs.acs.org.

\section{Literature Cited}

(1) Lyday, T. Q. The mineral industry of Papua New Guinea. In U.S Geological Survey Minerals Yearbook 2001; U.S. Geological Survey: Reston, VA, 2001; Chapter 20, pp 1-5.

(2) Lihir Gold Mine Environmental Impact Statement for Production Improvement Program; Lihir Management Company Limited: Port Moresby, Papua New Guinea, 2005; Vol. B: Main Report, p 149.

(3) Brewer, D.; Dennis, D.; Fry, G.; Milton, D.; Dambacher, J.; van der Velde, T.; Manson, F.; Heales, D.; Koutsoukos, A.; Skewes, T.; Taranto, T.; Jones, P.; Venebles, B.; Wang, Y. G.; Macintyre, M.; Foale, S.; Blaber, S. Assessment of Mine Impacts on Lihir Island Fish Communities with an Estimate of the Potential Fisheries Resources; Final Project Report; CSIRO Marine Research: Hobart, Tasmania, Australia, 2004; p 463.

(4) Macintyre, M.; Foale, S. Politicised ecology: Local responses to mining in Papua New Guinea. Oceania 2004, 74, 231251.

(5) Myers, N. The question of linkages in environment and development. Bioscience 1993, 43, 302-310.

(6) Yodzis, P. Food webs and perturbation experiments: theory and practice. In Food Webs: Integration of Patterns and Process; Polis, G. A., Winemiller, K. O., Eds.; Chapman Hall: New York, 1995; pp 192-200.

(7) Levins, R. The strategy of model building in population biology. Am. Sci. 1966, 54, 421-431.

(8) Levins, R. Qualitative mathematics for understanding, prediction and intervention in complex ecosystems. In Ecosystem Health: Principles and Practices; Rapport, D., Costanza, R., Epstein, P. R., Gaudet, C., Levins, R., Eds.; Blackwell Science: Malden, MA, 1998; pp 178-204.

(9) Puccia, C. J.; Levins, R. Qualitative Modeling of Complex Systems: An Introduction to Loop Analysis and Time Averaging; Harvard University Press: Cambridge, MA, 1985; p 259.

(10) Samuelson, P. A. Foundations of Economic Analysis, enlarged ed.; Harvard Economic Studies; Harvard University Press: Cambridge, MA, 1983; Vol. 80 p 604.

(11) Quirk, J.; Ruppert, R. Qualitative economics and the stability of equilibrium. Rev. Econ. Stud. 1965, 32, 311-326.

(12) Levins, R. The qualitative analysis of partially specified systems Ann. N. Y. Acad. Sci. 1974, 231, 123-138.

(13) Levins, R. Evolution in communities near equilibrium. In Ecology and Evolution of Communities; Cody, M., Diamond, J. M., Eds.; Harvard University Press: Cambridge, MA, 1975; pp 1650 .

(14) Levins, R. Coexistence in a variable environment. Am. Nat. 1979, 114, 765-783.

(15) Kuipers, B. Qualitative Reasoning: Modeling and Simulation with Incomplete Knowledge; MIT Press: Cambridge, MA, 1994, p 418.

(16) Benaroch, M.; Dhar, V. Controlling the complexity of investment decisions using qualitative reasoning techniques. Decis. Support Syst. 1995, 15, 115-131.

(17) Bredeweg, B.; Salles, P. Qualitative reasoning about population and community ecology. Artif. Intell. 2003, 24, 77-99.

(18) Eisenack, K.; Welsh, H.; Kropp, J. P. A qualitative dynamical modelling approach to capital accumulation in unregulated fisheries. J. Econ. Dyn. Control 2006, 30, 2613-2636. 
(19) Leontief, W. Input-Output Economics, 2nd ed.; Oxford University Press: New York, 1986; p 436.

(20) Rappaport, R. A. Pigs for the Ancestors: Ritual in the Ecology of a New Guinea People, 2nd ed.; Yale University Press: New Haven, CT, 1984; p 501.

(21) Jostad, P. M.; McAvoy, L. H.; McDonald, D. Native American land ethics: implications for natural resource management. Soc. Nat. Resour. 1996, 9, 565-581.

(22) Farrell, K.N. How much for your wife? A critique of the pragmatic assigning of monetary values to ecological phenomena. Paper presented at the 53rd Annual Conference of the Political Studies Association, University of Leicester, England, April 15-17, 2003; p 42.

(23) Dambacher, J. M.; Li, H. W.; Rossignol, P. A. Relevance of community structure in assessing indeterminacy of ecological predictions. Ecology 2002, 83, 1372-1385.

(24) Dambacher, J. M.; Luh, H.-K.; Li, H. W.; Rossignol, P. A. Qualitative stability and ambiguity in model ecosystems. Am. Nat. 2003, 161, 876-888.

(25) Dambacher, J. M.; Li, H. W.; Rossignol, P. A. Qualitative predictions in model ecosystems. Ecol. Modell. 2003, 161, 7993.

(26) FishBase; Froese, R., Pauly, D., Eds.; electronic publication, www.fishbase.org, May 2005 version.

(27) Chabanet, P.; Ralambondrainy, H.; Amanieu, M.; Faure, G.; Galzin, R. Relationships between coral reef substrata and fish. Coral Reefs 1997, 16, 93-102.
(28) McCook, J. L.; Jompa, J.; Diaz-Pulido, G. Competition between corals and algae on coral reefs: a review of evidence and mechanisms. Coral Reefs 2001, 19, 400-417.

(29) Macintyre, M.; Foale, S. Social and Economic Impact Study Lihir; Charlotte Allen and Associates: Melbourne, Victoria, Australia, 2003; p 100.

(30) Young, M. W. Fighting with Food: Leadership, Values and Social Control in a Massim Society; Cambridge University Press: London, 1971; p 282.

(31) Umar, M. J.; McCook, L. J.; Price, I. R. Effects of sediment deposition on the seaweed Sargassum on a fringing coral reef. Coral Reefs 1998, 17, 169-177.

(32) Fabricius, K. E.; Wolanski, E. Rapid smothering of coral reef organisms by muddy marine snow. Estuarine, Coastal Shelf Sci. 2000, 50, 115-120.

(33) McCook, L. J. Macroalgae, nutrients and phase shifts on coral reefs: scientific issues and management consequences for the Great Barrier Reef. Coral Reefs 1999, 18, 357367.

Received for review May 1, 2006. Revised manuscript received November 1, 2006. Accepted November 1, 2006.

ES0610333 